\title{
VIABILIDADE AGRONÔMICA DE POLICULTIVOS DE RÚCULA/CENOURA/ ALFACE SOB QUANTIDADES DE FLOR-DE-SEDA E DENSIDADES POPULACIONAIS ${ }^{1}$
}

\author{
LENILTON ALEX DE ARAÚJO OLIVEIRA ${ }^{2}$, FRANCISCO BEZERRA NETO*2, MAIELE LEANDRO DA SILVA ${ }^{2}$, \\ OCIMARA FERNANDES NEGREIROS OLIVEIRA ${ }^{2}$, JAILMA SUERDA SILVA DE LIMA², \\ AURÉLIO PAES BARROS JÚNIOR ${ }^{2}$
}

\begin{abstract}
RESUMO - Este trabalho teve como objetivo estudar a viabilidade agronômica do bicultivo de rúcula (R) e alface consorciado (A) com cenoura (C) sob diferentes quantidades de flor-de-seda incorporadas ao solo e de proporções de densidades populacionais entre as culturas componentes no semiárido do Estado do Rio Grande do Norte. O delineamento experimental foi de blocos completos casualizados com quatro repetições, com os tratamentos arranjados em esquema fatorial 4 × 4 . O primeiro fator foi constituído pelas quantidades de flor-de-seda incorporadas ao solo $\left(10,25,40\right.$ e $55 \mathrm{t} \mathrm{ha}^{-1}$ em base seca) e o segundo fator pelas proporções de densidades populacionais das culturas componentes em policultivo [(50R-50C-50A (\%); 40R-50C-40A (\%); 30R-50C-30A (\%) e 20R-50C-20A (\%) das populações recomendadas em cultivos solteiro - PRCS)]. As folhosas foram plantadas em dois cultivos no ciclo da cenoura e uma análise conjunta foi realizada envolvendo os dois cultivos da rúcula e da alface e o fatorial 4 × 4 . As características avaliadas foram: rendimento de massa verde (rúcula); massa seca da parte aérea e produtividade (alface); produtividade total; comercial; e classificada de raízes de cenoura. A vantagem monetária corrigida foi usada para avaliar a viabilidade agronômica dos sistemas consorciados. O uso da flor-de-seda como adubo verde se mostrou viável no policultivo de rúcula, cenoura e alface. O melhor desempenho agronômico do policultivo de rúcula, cenoura e alface foi registrado na quantidade de $55 \mathrm{t} \mathrm{ha}^{-1} \mathrm{de}$ flor-de-seda incorporada ao solo. As proporções de densidades populacionais de rúcula, cenoura e alface de 5050-50 (\%) das PRCS foram as que proporcionaram a maior viabilidade agronômica dos policultivos.
\end{abstract}

Palavras-chave: Associação de culturas. Eruca sativa. Daucus carota. Lactuca sativa. Calotropis procera.

\section{AGRONOMIC FEASIBILITY OF POLYCULTURES OF ARUGULA/CARROT/LETTUCE UNDER AMOUNTS OF ROOSTERTREE AND POPULATION DENSITIES}

\begin{abstract}
This work aimed to study the agronomic feasibility of the arugula (A) and lettuce (L) bicropping intercropped with carrot $(\mathrm{C})$ under different amounts of roostertree incorporated into the soil and proportions of population densities among component crops in semiarid conditions of the Rio Grande do Norte state. The experimental design was randomized complete block with four replications, with the treatments arranged in a factorial $4 \times 4$. The first factor was constituted by the amounts of roostertree incorporated into the soil $\left(10,25,40\right.$ and $55 \mathrm{t} \mathrm{ha}^{-1}$ on a dry basis) and the second factor by the proportions of population densities of the component crops in polyculture [(50A-50C-50L (\%); 40A-50C-40L (\%); 30A-50C-30L (\%) and 20A-50C20L (\%) of the recommended populations in sole crops - RPSC)]. The leafy vegetable crops were planted in two cultivations during the carrot cycle, and a joint analysis was carried out involving the two cultivations in the $4 \times 4$ factorial scheme. The characteristics evaluated were green mass yield (arugula), dry mass of shoots and productivity (lettuce), total, commercial and classified productivity of carrot roots. The modified monetary advantage was used to evaluate the agronomic feasibility of intercropping systems. The use of roostertree as green manure proved viable in the polyculture of arugula, carrot, and lettuce. The major agronomic perfor-

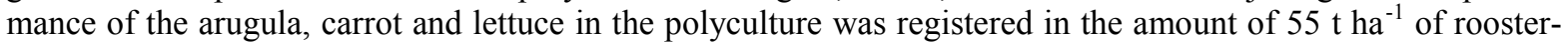
tree incorporated into the soil. The population density proportions of arugula, carrot and lettuce of 50A-50C$50 \mathrm{~L}(\%)$ of the RPSC were those that provided the greatest agronomic feasibility of the polycultures.
\end{abstract}

Keywords: Intercropping. Eruca sativa. Daucus carota. Lactuca sativa. Calotropis procera.

\footnotetext{
*Autor para correspondência

${ }^{1}$ Recebido para publicação em 20/01/2015; aceito em 28/09/2015.

Tese de Doutorado em Fitotecnia: Agronomia do primeiro autor.

${ }^{2}$ Departamento de Ciências Vegetais UFERSA, BR 110, Km 47, s/n, 59625-900 Mossoró (RN); lenilton@ufersa.edu.br, bezerra@ufersa.edu.br, maiele_engenharia@yahoo.com.br,oci_mara@hotmail.com,jailma@ufersa.edu.br, aurelio.barros@ufersa.edu.br.
} 


\section{INTRODUÇ̃̃̃O}

Nos últimos anos tem se observado um crescente consumo de hortaliças decorrente de uma maior conscientização da população por uma dieta alimentar mais rica e saudável. Diante disso, surge a necessidade de desenvolvimento de sistemas de cultivos com hortaliças que assegure o equilíbrio do ambiente e de seus recursos e amplie o desafio em gerar soluções e práticas culturais ambientalmente desejáveis (TAVELLA et al., 2010; LINHARES et al., 2013). Entre essas práticas está a consorciação de culturas, a qual tem sido objeto de estudos e vem se constituindo em uma alternativa com viabilidade agroeconômica e sustentável, além de aumentar a produção de alimentos por unidade de área, proporcionando maior diversidade biológica, elevada proteção do solo, melhor eficiência de uso da terra e aumento no aproveitamento de recursos e insumos utilizados nos cultivos (REZENDE et al., 2005; LIMA et al., 2013). O sucesso de um sistema consorciado de culturas depende de seu manejo em relação a fatores de produção como quantidades de adubo, proporções de densidades populacionais e escolha das culturas envolvidas no sistema.

A adubação verde com espécies espontâneas da Caatinga tem sido realizada em algumas oleráceas no Nordeste do Brasil e tem demonstrado resultados promissores. A jitirana (Merremia aegyptia L.) tem sido usada na adubação de alface (BEZERRA NETO et al., 2011; GÓES et al., 2011), de rúcula (PEREIRA et al., 2011), coentro (LINHARES et al., 2012) e cenoura (BEZERRA et al., 2014; OLIVEIRA, 2012b), bem como a flor-de-seda [(Calotropis procera Ait) R.Br.] nas culturas de rúcula (LINHARES et al., 2009), alface (LIMA, 2012) e cenoura (SILVA et al., 2013). O grande desafio tem sido encontrar a quantidade adequada que maximize a produtividade dos sistemas consorciados com essas hortaliças quando adubadas com flor-de-seda.

A proporção de densidades populacionais é outro fator de produção que tem sido usado em sistemas consorciado de espécies cultivadas, e seu uso em hortaliças é crescente. Com o manejo desse fator objetiva-se a redução do ciclo, o aumento da eficiência no aproveitamento de insumos aplicados (fertilizantes e agrotóxicos) e recursos disponíveis (água, luz e nutrientes) e o aumento da produtividade (LOPES et al., 2008). Segundo Choairy e Fernandes (1983), as vantagens nesse sistema se encerram quando se atinge o ponto de competição. O entendimento da competição entre plantas é de fundamental importância nesses sistemas de cultivo, uma vez que a eficiência de um sistema associado fundamenta-se principalmente na complementaridade entre as culturas envolvidas, sendo que esta será maior na medida em que se consegue minimizar os efeitos estabelecidos de uma espécie sobre a outra (PORTO et al., 2011). Portanto, propostas de espaçamento e densidade de plantio para as culturas em geral têm procu- rado atender as necessidades especificas dos tratos culturais e melhoria da produtividade (BEZERRA NETO et al., 2005).

Lima et al. (2013), estudando o policultivo de rúcula, cenoura e coentro em função de densidades populacionais, observaram que o maior desempenho agroeconômico do sistema foi registrado na densidade populacional de $30 \% \mathrm{R}-50 \% \mathrm{C}-30 \% \mathrm{Co}$.

Nesse contexto, o presente trabalho teve por objetivo avaliar a viabilidade agronômica de dois cultivos de rúcula e de alface consorciados com cenoura em policultivo sob diferentes quantidades de flor-de-seda incorporadas ao solo e proporções de densidades populacionais nas condições semiáridas de Mossoró (RN).

\section{MATERIAL E MÉTODOS}

O experimento foi conduzido na Fazenda Experimental Rafael Fernandes, pertencente à Universidade Federal Rural do Semi-Árido (UFERSA), localizada no distrito de Alagoinha, zona rural de Mossoró (RN) (5'03'37'S e $37^{\circ} 23^{\prime} 50^{\prime}$ 'W Gr), no período de agosto a dezembro de 2012, $20 \mathrm{~km}$ da cidade citada. Segundo Thornthwaite, o clima local é DdAa', ou seja, semiárido (CARMO FILHO et al., 1991). Durante o período experimental a temperatura média foi de $27^{\circ} \mathrm{C}$, a mínima de $25{ }^{\circ} \mathrm{C}$ e a máxima de $31{ }^{\circ} \mathrm{C}$, com umidade relativa média do ar de $66 \%$, velocidade do vento média de $4 \mathrm{~m} \mathrm{~s}^{-1}$, radiação média de $918 \mathrm{~kJ} \mathrm{~m}^{-2}$, precipitação pluviométrica de $0 \mathrm{~mm}$, pressão atmosférica média de $1011 \mathrm{hPa}$ e temperatura média do ponto de orvalho de $19{ }^{\circ} \mathrm{C}$.

O solo da área experimental foi classificado como Latossolo Vermelho Amarelo Distrófico argissólico (EMBRAPA, 2006). Nessa área foram coletadas amostras de solo a uma camada de 0-20 cm e posteriormente enviadas para o Laboratório de Análises de Água, Solos e Plantas do Departamento de Ciências Ambientais da UFERSA para análise, obtendo-se os seguintes resultados: $\mathrm{pH}=5,51$; $\mathrm{CE}=2,81 \mathrm{dS} \mathrm{m}^{-1} ;$ M.O. = 0,8125\%; $\mathrm{P}=16,5 \mathrm{mg} \mathrm{dm} \mathrm{K}^{-3} ; \mathrm{K}^{+}=55,35 \mathrm{cmol}_{\mathrm{c}} \mathrm{dm}^{-3}$; $\mathrm{Ca}^{+2}=1,91 \mathrm{cmol}_{\mathrm{c}} \mathrm{dm}^{-3} ; \mathrm{Mg}^{+2}=1,05 \mathrm{cmol}_{\mathrm{c}} \mathrm{dm}^{-3} ; \mathrm{e}^{\mathrm{C}}$ $\mathrm{Na}^{+}=2,05 \mathrm{cmol}_{\mathrm{c}} \mathrm{dm}^{-3}$.

O delineamento experimental utilizado foi em blocos ao acaso com os tratamentos arranjados em esquema fatorial $4 \times 4$ com quatro repetições. O primeiro fator foi constituído pelas quantidades de florde-seda incorporadas ao solo $\left(10,25,40\right.$ e $55 \mathrm{t} \mathrm{ha}^{-1}$ em base seca) e o segundo fator pelas densidades populacionais (DPs) das culturas componentes em policultivo [(50R-50C-50A (\%), 40R-50C-40A (\%), 30R-50C-30A (\%) e 20R-50C-20A (\%) da população recomendada no cultivo solteiro - PRCS)]. O plantio das folhosas foi realizado em dois cultivos durante o ciclo da cenoura e uma análise conjunta foi realizada envolvendo os dois cultivos da rúcula e da 
alface no fatorial $4 \times 4$. As cultivares de hortaliças plantadas foram, respectivamente, 'Cultivada', 'Brasília' e 'Tainá'.

O cultivo consorciado foi estabelecido em faixas alternadas das culturas de rúcula e de alface entre as faixas de cenoura, na proporção da área ocupada de $50 \%$ para cenoura, $25 \%$ para rúcula e $25 \%$ para a alface, em que cada parcela foi constituída por quatro faixas de quatro fileiras, quais sejam: uma faixa de rúcula; uma faixa de cenoura; uma faixa de alface; e uma faixa de cenoura, ladeada em um lado da primeira faixa por uma faixa de cenoura e ladeada na última faixa por uma faixa de rúcula, usadas como bordaduras. A área total da parcela foi de $5,76 \mathrm{~m}^{2}$, com uma área útil de $3,20 \mathrm{~m}^{2}$.

Em cada bloco foram plantadas parcelas solteiras de rúcula, cenoura e alface para obtenção dos indicadores agronômicos. O cultivo solteiro de cada hortaliça foi estabelecido através do plantio de seis linhas por parcela, com uma área total de $1,44 \mathrm{~m}^{2} \mathrm{e}$ área útil contendo 80 plantas de rúcula no espaçamento de $0,20 \mathrm{~m} \times 0,05 \mathrm{~m}, 16$ plantas de alface no espaçamento de $0,20 \mathrm{~m} \times 0,20 \mathrm{~m}$ e 40 plantas de cenoura no espaçamento de $0,20 \mathrm{~m} \times 0,10 \mathrm{~m}$. A área útil foi constituída pelas quatro fileiras centrais, excluindo-se a primeira e última fileiras, bem como a primeira e a última plantas de cada fileira, usadas como bordaduras. Os níveis populacionais recomendados para o cultivo solteiro dessas hortaliças foram de 1.000.000 plantas por hectare para a rúcula (FREITAS et al., 2009), 500.000 plantas por hectare para a cenoura (OLIVEIRA et al., 2012a), e 250.000 plantas por hectare para alface (BEZERRA NETO et al., 2007).

O preparo do solo consistiu na limpeza mecânica com grade aradora seguida de uma gradagem e levantamento dos canteiros com enxada rotativa. Após isso foi realizada uma solarização em préplantio com plástico transparente tipo Vulcabrilho Bril Fles de 30 micras durante 30 dias com a finalidade de combater nematóides e fitoparasitas nas camadas $0-10 \mathrm{~cm}$ do solo, especialmente Meloidogyne spp (SILVA et al., 2006).

A flor-de-seda foi coletada da vegetação nativa do perímetro urbano da microrregião de Mossoró, triturados em pedaços de dois a três centímetros e colocados para secar em temperatura ambiente até atingirem ponto de fenação, sendo armazenada com teor de umidade de 8,3\%. Amostras desse adubo verde foram retiradas aleatoriamente para quantificação dos teores de nutrientes, cuja composição química obtida foi: $20,56 \mathrm{~g} \mathrm{~kg}^{-1} \mathrm{~N} ; 4,0 \mathrm{~g} \mathrm{~kg}^{-1} \mathrm{P}$; $35,7 \mathrm{~g} \mathrm{~kg}^{-1} \mathrm{~K} ; 9,3 \mathrm{~g} \mathrm{~kg}^{-1} \mathrm{Ca}$; e 7,03 $\mathrm{g} \mathrm{kg}^{-1} \mathrm{Mg}$, com relação carbono/nitrogênio de 25:1.

Foram realizadas duas incorporações do adubo verde nas parcelas dos cultivos consorciados e solteiro da cenoura, sendo $50 \%$ das quantidades de flor-de-seda incorporadas em todas as parcelas nos canteiros consorciados 20 dias antes da semeadura das culturas componentes e $50 \%$ restante incorpora- do 55 dias após o plantio da cenoura. A incorporação do adubo verde nos cultivos solteiros de rúcula e alface foi realizada 20 dias antes do plantio nas quantidades de 14,5 e $10,1 \mathrm{t} \mathrm{ha}^{-1}$, respectivamente, conforme dose otimizada em pesquisa (LINHARES, 2007; GÓES, 2007).

A semeadura das culturas da rúcula e da cenoura e do transplantio da alface foi realizada no dia $01 / 08 / 2012$. O plantio da rúcula e da cenoura foi feito em covas de três centímetros de profundidade, colocando-se três a quatro sementes por cova, e o transplantio da alface realizado também em covas. As mudas de alface para o transplantio foi adquirida de uma empresa local de produção de mudas na cidade de Mossoró (RN). Aos sete e quinze dias após a emergência foi realizado o desbaste apenas na cultura da rúcula e da cenoura, deixando-se duas plantas por cova na rúcula e uma planta por cova na cenoura com o intuito de ajustar as proporções de densidades populacionais estudadas.

O sistema de irrigação usado foi por microaspersão, com dois turnos de rega diário, um pela manhã e outro pela tarde, fornecendo-se uma lâmina de água de $8 \mathrm{~mm} \mathrm{dia}^{-1}$ com a finalidade de manter a umidade do solo entre 50 e $70 \%$ da capacidade de campo, sendo essa uma condição ideal para o processo de nitrificação (MEURER, 2007). O controle das plantas infestantes foi realizado através de capinas manuais sempre que necessário.

A colheita da rúcula foi realizada aos 35 dias após a semeadura e a da alface aos 30 dias após o transplantio. $\mathrm{O}$ segundo cultivo da cultura da rúcula e do transplante da alface foi realizado no dia $01 / 11 / 2012$. Os tratos culturais seguiram o mesmo padrão do primeiro cultivo e a colheita foi realizada também aos 35 e 30 dias da semeadura da rúcula e do transplantio da alface, respectivamente. A colheita da cenoura ocorreu aos 105 dias após plantio.

As características avaliadas na cultura da rúcula foram: massa seca da parte aérea (tomada de uma amostra de vinte plantas, na qual fora determinada a massa seca em estufa com circulação forçada de ar na temperatura de $65{ }^{\circ} \mathrm{C}$ até atingir peso constante, expressa em $\mathrm{t} \mathrm{ha}^{-1}$ ); e o rendimento de massa verde (avaliado através da massa fresca da parte aérea de todas as plantas da área útil, expresso em $\left.\mathrm{tha}^{-1}\right)$.

Para a cultura da cenoura foram determinadas a produtividade classificada de raízes, obtida segundo o comprimento e maior diâmetro transversal em longas (comprimento de 17 a $25 \mathrm{~cm}$ e diâmetro menor que $5 \mathrm{~cm}$ ), médias (comprimento de 12 a $17 \mathrm{~cm} \mathrm{e}$ diâmetro maior que $2,5 \mathrm{~cm}$ ), curtas (comprimento de 5 a $12 \mathrm{~cm}$ e diâmetro maior que $1 \mathrm{~cm}$ ) e refugo (raízes que não se enquadram nas medidas anteriores), conforme Lana e Vieira (2000). Essa produtividade foi expressa em $t$ ha $^{-1}$. A produtividade comercial foi quantificada a partir da massa fresca das raízes longas, médias e curtas da área útil da parcela, expressa em $\mathrm{t} \mathrm{ha}^{-1}$. Foram consideradas como produ- 
tividade comercial as raízes livres de rachaduras, bifurcações, nematóides e danos mecânicos e produtividade total, obtida pela adição da produtividade comercial com a de refugo, expressa em $\mathrm{tha}^{-1}$.

$\mathrm{Na}$ cultura da alface foram avaliadas as seguintes características: massa seca da parte aérea (avaliada em uma amostra de oito plantas, em estufa com circulação forçada de ar a temperatura de $65{ }^{\circ} \mathrm{C}$ até atingir peso constante, expressa em $\mathrm{t} \mathrm{ha}^{-1}$ ) e produtividade (avaliada através da massa fresca da parte aérea de todas as plantas da área útil, expressa em $\left.\mathrm{tha}^{-1}\right)$.

Com a finalidade de determinar a melhor eficiência agronômica dos sistemas consorciados, os dados foram analisados através da vantagem monetária corrigida (VMc), obtida pela seguinte equação: $\left(\mathrm{R} \$ \mathrm{ha}^{-1}\right)$;

$\mathrm{VMc}=\mathrm{RL} \times(\mathrm{UET}-1) / \mathrm{UET}$, em que:

$\mathrm{VMc}$ - vantagem monetária corrigida

$\mathrm{RL}$ - renda líquida por hectare $\left(\mathrm{R} \$ \mathrm{ha}^{-1}\right)$ representada pela equação $\mathrm{RL}=\mathrm{RB}-\mathrm{CT}$.

$\mathrm{RB}$ significa renda bruta e CT custos totais de produção. A metodologia para a sua obtenção foi aquela utilizada por Silva et al. (2015), em que os custos totais de produção foram calculados no final do processo produtivo baseado nos gastos totais por hectare de área cultivada, os quais abrangem os serviços prestados pelo capital estável, ou seja, a contribuição do capital circulante e o valor dos custos alternativos ou de oportunidades.

UET - índice de uso eficiente da terra do policultivo, definido pela seguinte expressão:

$\mathbf{U E T}=\left(\mathbf{Y}_{\mathrm{rpc} 1} / \mathbf{Y}_{\mathrm{rrc1}}\right)+\left(\mathbf{Y}_{\mathrm{rpc} 2} / \mathbf{Y}_{\mathrm{rrc} 2}\right)+$ $\left(\mathbf{Y}_{\mathrm{cp}} / \mathbf{Y}_{\mathrm{cc}}\right)+\left(\mathbf{Y}_{\mathrm{apc} 1} / \mathbf{Y}_{\mathrm{aac} 1}\right)+\left(\mathbf{Y}_{\mathrm{apc} 2} / \mathbf{Y}_{\mathrm{aac} 2}\right)$, onde:

$\mathrm{Y}_{\mathrm{rpcl}}=$ Rendimento de massa verde de rúcula em policultivo com cenoura e alface no primeiro cultivo; $\mathrm{Y}_{\mathrm{rrc} 1}=$ Rendimento de massa verde de rúcula em cultura solteira no primeiro cultivo;

$\mathrm{Y}_{\mathrm{rpc} 2}=$ Rendimento de massa verde de rúcula em policultivo com cenoura e alface no segundo cultivo; $\mathrm{Y}_{\mathrm{rrc} 2}=$ Rendimento de massa verde de rúcula em cultura solteira no segundo cultivo;

$\mathrm{Y}_{\mathrm{cp}}=$ Produtividade comercial de raízes de cenoura em policultivo com rúcula e alface;

$\mathrm{Y}_{\mathrm{cc}}=$ Produtividade comercial de raízes de cenoura em cultura solteira;

$\mathrm{Y}_{\mathrm{apcl}}=$ Produtividade de alface em policultivo com cenoura e rúcula no primeiro cultivo;

$\mathrm{Y}_{\mathrm{acc}}=$ Produtividade de alface em cultura solteira no primeiro cultivo;
$\mathrm{Y}_{\mathrm{apc} 2}=$ Produtividade de alface em policultivo com cenoura e rúcula no segundo cultivo;

$\mathrm{Y}_{\mathrm{aac} 2}=$ Produtividade de alface em cultura solteira no segundo cultivo.

As UET's de cada parcela foram obtidas considerando-se o valor da média das repetições dos cultivos solteiros sobre blocos no denominador dos índices de uso eficiente da terra parciais de cada cultura (UETr, UETc e UETa), conforme recomendação de Federer (2002).

Foram realizadas análises univariada de variância nas características das culturas componentes e do sistema consorciado através do pacote estatístico SISVAR (FERREIRA, 2011) para o delineamento em blocos completos casualizados com os tratamentos arranjados em esquema fatorial. Uma análise conjunta também foi realizada envolvendo os dois cultivos da rúcula e da alface no esquema fatorial $4 \times 4$. O teste de Tukey ao nível de 5\% de probabilidade foi usado na comparação das médias entre as proporções de densidades populacionais das oleráceas. Procedimento de ajustamento de curvas de resposta foi feito em cada variável em função das quantidades de florde-seda incorporadas ao solo através do software Table Curve (JANDEL SCIENTIFIC, 1991).

\section{RESULTADOS E DISCUSSÃO}

\section{Cultura da rúcula}

Interação significativa entre as quantidades de flor-de-seda e os cultivos de rúcula foi registrada no rendimento de massa verde e massa seca da parte aérea de rúcula, com aumento dessas variáveis de aproximadamente 0,646 e $2,128 \mathrm{t} \mathrm{ha}^{-1}$ e de $0,014 \mathrm{e}$ $0,091 \mathrm{tha}^{-1}$ nos cultivos 1 e 2 , respectivamente, entre a menor $\left(10 \mathrm{tha}^{-1}\right)$ e a maior $\left(55 \mathrm{tha}^{-1}\right)$ quantidade de adubo incorporada, com valores máximos de rendimento de 2,198 e 5,993 $\mathrm{t} \mathrm{ha}^{-1}$ e de massa seca de aproximadamente 0,096 e $0,202 \mathrm{t} \mathrm{ha}^{-1}$ no primeiro e segundo cultivos (Figuras 1A e 1B). Esses maiores valores de rendimento e de massa seca não se deve apenas a segunda época de cultivo da rúcula, plantada 15 dias antes da colheita da cenoura, como também ao melhor aproveitamento dos recursos ambientais (água, luz, adubo etc.) pela folhosa sem forte competição interespecífica com a cenoura. 

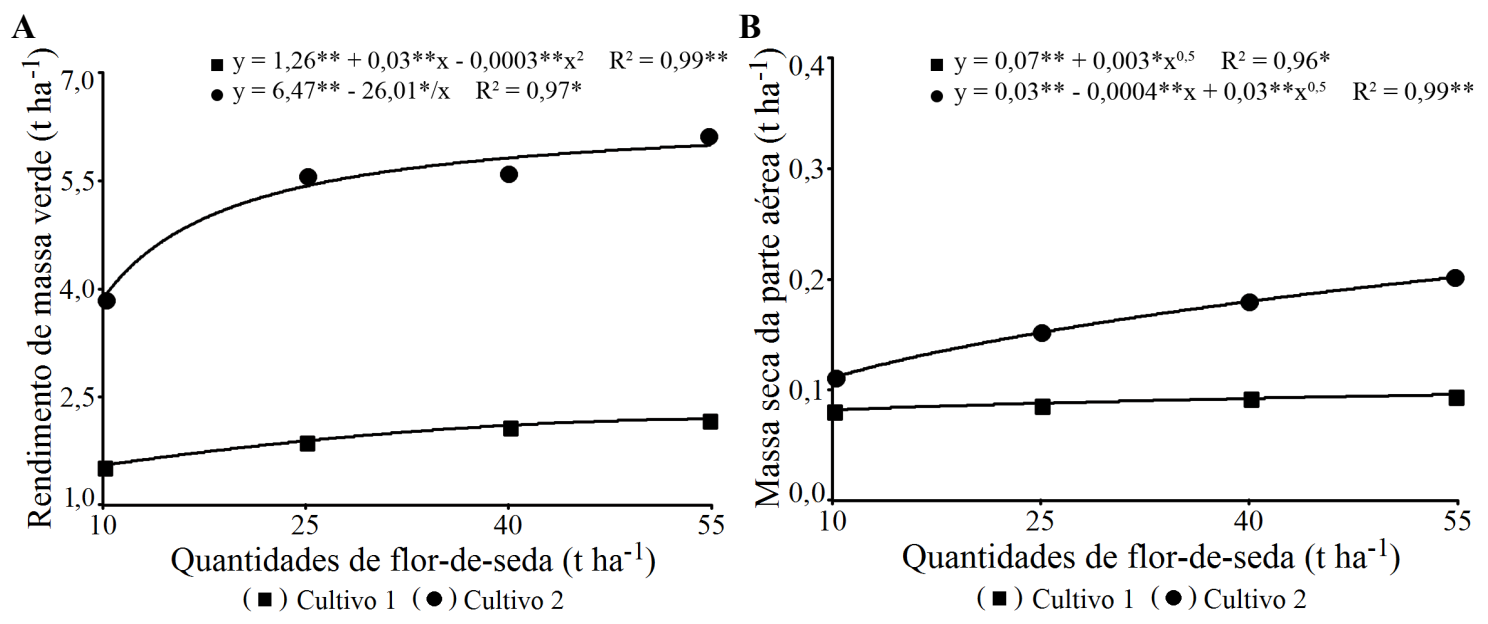

Figura 1. Rendimento de massa verde (A) e massa seca da parte aérea (B) de rúcula proveniente do desdobramento da interação das quantidades de flor-de-seda em função dos dois cultivos. Mossoró (RN), UFERSA, 2012.

Desdobrando os cultivos de rúcula dentro de cada quantidade de flor-de-seda adicionada ao solo observou-se que o rendimento de massa verde e massa seca da parte aérea registraram os maiores valores médios no cultivo 2 , exceto dentro da quantidade de adubo incorporada de $10 \mathrm{tha}^{-1}$, em que as médias da massa seca não diferiram entre si (Tabela 1).

Tabela 1. Rendimento de massa verde (RMV) e massa seca da parte aérea (MSPA) de rúcula consorciada com cenoura e alface em dois cultivos em diferentes proporções de densidades populacionais e quantidades de flor-de-seda incorporadas ao solo. Mossoró (RN), UFERSA, 2012.

\begin{tabular}{|c|c|c|c|c|}
\hline Proporções de densidades populacionais (\%) & $\operatorname{RMV}\left(\mathrm{t} \mathrm{ha}^{-1}\right)$ & \multicolumn{3}{|c|}{$\operatorname{MSPA}\left(\mathrm{t} \mathrm{ha}^{-1}\right)$} \\
\hline 50R-50C-50A & $4,24 \mathrm{a}^{*}$ & \multicolumn{3}{|c|}{$0,11 \mathrm{a}$} \\
\hline $40 \mathrm{R}-50 \mathrm{C}-40 \mathrm{~A}$ & 3,93 a & \multicolumn{3}{|c|}{$0,12 \mathrm{a}$} \\
\hline $30 \mathrm{R}-50 \mathrm{C}-30 \mathrm{~A}$ & $3,54 \mathrm{~b}$ & \multicolumn{3}{|c|}{$0,13 \mathrm{a}$} \\
\hline 20R-50C-20A & $2,81 \mathrm{~b}$ & \multicolumn{3}{|c|}{$0,14 \mathrm{a}$} \\
\hline Quantidades de flor-de-seda $\left(\mathrm{t} \mathrm{ha}^{-1}\right)$ & Cultivo 1 & Cultivo 2 & Cultivo 1 & Cultivo 2 \\
\hline 10 & $1,55 \mathrm{~B}$ & $3,86 \mathrm{~A}$ & $0,083 \mathrm{~A}$ & $0,111 \mathrm{~A}^{*}$ \\
\hline 25 & $1,90 \mathrm{~B}$ & $5,56 \mathrm{~A}$ & $0,087 \mathrm{~B}$ & $0,152 \mathrm{~A}$ \\
\hline 40 & $2,10 \mathrm{~B}$ & $5,57 \mathrm{~A}$ & $0,095 \mathrm{~B}$ & $0,180 \mathrm{~A}$ \\
\hline 55 & $2,20 \mathrm{~B}$ & $6,13 \mathrm{~A}$ & $0,095 \mathrm{~B}$ & $0,202 \mathrm{~A}$ \\
\hline $\mathrm{CV}(\%)$ & 32,72 & & 41,97 & \\
\hline
\end{tabular}

*Médias seguidas pela mesma letra minúscula na coluna ou maiúscula na linha não diferem estatisticamente entre si pelo teste de Tukey ao nível de $5 \%$ de probabilidade.

Esses resultados da rúcula confirmam a eficiente resposta dessa olerácea a adubação orgânica, corroborando com as observações feitas por Filgueira (2003) ao reportar que a eficiência do adubo orgânico está relacionada ao aumento da parte aérea e do rendimento de massa verde das plantas devido ao aumento da disponibilidade de nutrientes e favorecimento das propriedades físicas e as atividades dos organismos do solo.

Diferenças significativas entre os valores médios de rendimento da massa verde da rúcula entre as proporções de densidades populacionais foram registradas com as proporções de 50R-50C-50A (\%) e 40R-50C-40A (\%) das populações recomendadas para os cultivos solteiros das culturas componentes, sobressaindo-se das demais (Tabela 1). Esses resultados se devem ao maior número de plantas por área, proporcionando maiores rendimentos da massa verde da rúcula. Por outro lado, não se observou diferença significativa entre os valores da massa seca da parte da rúcula entre as proporções populacionais testadas. Sabe-se que a medida que o espaçamento diminui dentro das fileiras a densidade populacional aumenta, e dentro de certos limites a produção da matéria seca por área poderá ficar estável ou com baixa variação devido o nível de competição não ser forte a ponto de alterar o seu comportamento. Pelos resultados obtidos foi isso o que aconteceu com a massa seca da rúcula em função das proporções populacionais.

Oliveira (2012a), trabalhando com o policultivo de rúcula $(\mathrm{R})$, cenoura $(\mathrm{C})$ e coentro $(\mathrm{Co})$ nas condições semiáridas do estado do Rio Grande do Norte, relatou que o melhor desempenho agronômico da rúcula no policultivo foi obtido na quantidade de $17,15 \mathrm{t} \mathrm{ha}^{-1}$ de jitirana incorporada ao solo na proporção de densidade populacional de 
20R-50C-20Co (\%) das DPs das culturas componentes em cultivos solteiros, cujos resultados são diferentes dos obtidos nesta pesquisa. Provavelmente, essa diferença se deve ao tipo de adubo verde utilizado e suas quantidades testadas, já que as épocas de cultivos foram praticamente as mesmas.

\section{Cultura da alface}

Não houve interação significativa entre qualquer um dos fatores-tratamentos (cultivos de alface, quantidades de flor-de-seda incorporadas ao solo e proporções de densidades populacionais entre as culturas componentes) na massa seca da parte aérea da alface (Figura 2A e Tabela 2). Foi registrado um aumento na massa seca da parte aérea com o aumento das quantidades de flor-de-seda até o valor máximo de $0,088 \mathrm{tha}^{-1}$ na dose de $45,48 \mathrm{t} \mathrm{ha}^{-1}$, decrescendo em seguida até a última dose adicionada ao solo (Figura 2A).

Tabela 2. Massa seca da parte aérea e produtividade da alface em diferentes proporções de densidades populacionais das culturas componentes dentro de quantidades de flor-de-seda incorporadas ao solo e em dois cultivos. Mossoró (RN), UFERSA, 2012.

\begin{tabular}{|c|c|c|c|c|c|}
\hline \multirow{3}{*}{$\begin{array}{l}\text { Proporções de densidades } \\
\text { populacionais }(\%)\end{array}$} & \multirow{3}{*}{$\begin{array}{l}\text { Massa seca da parte } \\
\text { aérea }\left(\mathrm{t} \mathrm{ha}^{-1}\right)\end{array}$} & \multicolumn{4}{|c|}{ Quantidades de flor-de-seda $\left(\mathrm{t} \mathrm{ha}^{-1}\right)$} \\
\hline & & 10 & 25 & 40 & 55 \\
\hline & & \multicolumn{4}{|c|}{ Produtividade $\left(\mathrm{t} \mathrm{ha}^{-1}\right)$} \\
\hline 50R-50C-50A & $0,071 \mathrm{~b}^{*}$ & $3,09 \mathrm{a}$ & $4,72 \mathrm{a}$ & $4,25 \mathrm{a}$ & $5,28 \mathrm{a}$ \\
\hline 40R-50C-40A & $0,078 \mathrm{ab}$ & $3,23 \mathrm{a}$ & $3,72 \mathrm{~b}$ & $3,81 \mathrm{a}$ & $3,89 \mathrm{~b}$ \\
\hline 30R-50C-30A & $0,082 \mathrm{ab}$ & $2,11 b$ & $2,92 \mathrm{c}$ & $2,87 \mathrm{~b}$ & $3,30 \mathrm{bc}$ \\
\hline 20R-50C-20A & $0,086 \mathrm{a}$ & $1,49 \mathrm{~b}$ & $1,95 \mathrm{~d}$ & $2,68 \mathrm{~b}$ & $2,70 \mathrm{c}$ \\
\hline \multicolumn{6}{|l|}{ Cultivos } \\
\hline Cultivo 1 & $0,071 \mathrm{~b}$ & & $3,09 \mathrm{~b}$ & & \\
\hline Cultivo 2 & $0,087 \mathrm{a}$ & & $3,40 \mathrm{a}$ & & \\
\hline CV (\%) & 22,75 & 41,86 & & & \\
\hline
\end{tabular}

*Médias seguidas por letras minúsculas diferentes na coluna diferem estatisticamente entre si pelo teste de Tukey ao nível $5 \%$ de probabilidade.
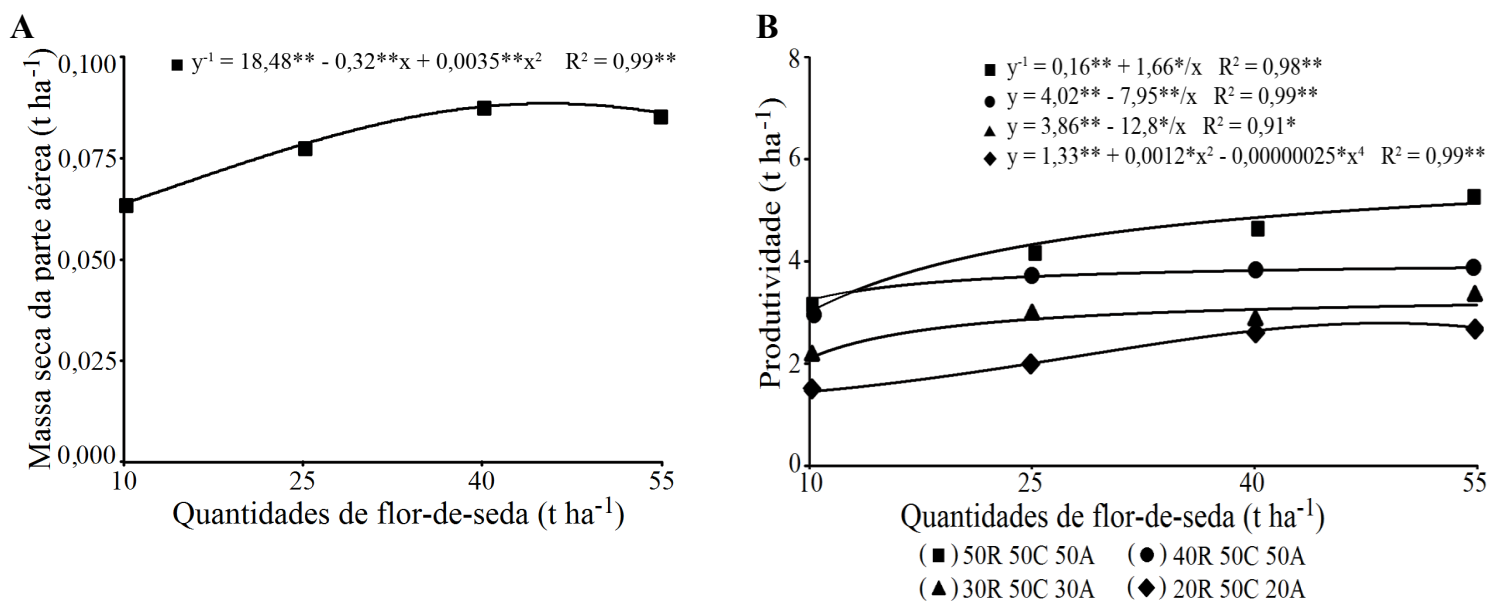

Figura 2. Massa seca da parte aérea da alface (A) em diferentes quantidades de flor-de-seda e produtividade da alface (B) consorciada com cenoura e rúcula em diferentes quantidades de adubo e proporções de densidades populacionais das culturas componentes. Mossoró (RN), UFERSA, 2012.

Interação significativa entre as quantidades de flor-de-seda e as proporções de densidades populacionais das culturas componentes foi registrada na produtividade da alface (Figura 2B). Um aumento com as quantidades de flor-de-seda foi observado na proporção 20R-50C-20A até o valor máximo de $2,81 \mathrm{t} \mathrm{ha}^{-1}$ na dose 48,94 $\mathrm{tha}^{-1}$, diminuindo em seguida até a última dose adicionada ao solo (Figura 2B). Por outro lado, incrementos nas produtividades da ordem 2,12, 0,65 e 1,04 $\mathrm{t} \mathrm{ha}^{-1}$ nas proporções populacionais $50 \mathrm{R}-50 \mathrm{C}-50 \mathrm{~A}, 40 \mathrm{R}-50 \mathrm{C}-40 \mathrm{~A}$ e $30 \mathrm{R}-$ $50 \mathrm{C}-30 \mathrm{~A}$ foram observados com as quantidades crescentes de flor-de-seda entre a menor $\left(10 \mathrm{t} \mathrm{ha}^{-1}\right) \mathrm{e}$ a maior $\left(55 \mathrm{t} \mathrm{ha}^{-1}\right)$ dosagem, com valores máximos de 5,14, 3,88 e 3,15 $\mathrm{t} \mathrm{ha}^{-1}$ (Figura 2B).

Esses resultados com a alface refletem a importância sobre a quantidade adequada de flor-deseda que deve ser aplicada ao solo para aumentar a produtividade das hortaliças e fornecer nutrientes em concentrações que permita a utilização eficiente pelas plantas sem ocasionar alterações negativas às propriedades do solo e ao crescimento e desenvolvimento das plantas. Eles estão em consonância com as observações reportadas por Filgueira (2003) ao 
observar que a eficiência de um adubo orgânico está relacionada a sua composição química, em fornecer nutrientes às plantas, por favorecer as propriedades físicas do solo e contribuir com as atividades dos organismos do solo favorecendo a absorção dos nutrientes pelas plantas.

Foi observada diferença significativa entre os valores médios de massa seca da parte aérea com a proporção de 20R-50C-20A sobressaindo-se das demais. Esse resultado se deve a maior absorção de água pelas plantas nas maiores densidades populacionais, já que nessa mesma proporção foi registrada a menor produtividade. Entre os cultivos de alface, essa característica avaliada teve desempenho significativamente melhor no segundo cultivo. Isso se deve ao fato desse cultivo ter sido realizado no fim do ciclo da cenoura, em que a competição interespecífica foi menor (Tabela 2).

Na produtividade da alface, os maiores valores médios foram observados na proporção 50R-50C-50A nas doses de 25 e $55 \mathrm{t} \mathrm{ha}^{-1}$ do adubo verde, enquanto que nas outras doses o melhor desempenho produtivo da alface foi observado nas proporções de 50R-50C-50A e 40R-50C-40A (Tabela 2). Entre os cultivos de alface, a produtividade teve desempenho significativamente superior no segundo cultivo.

As proporções das densidades populacionais combinadas contribuíram com o efeito benéfico da complementaridade entre as culturas, proporcionando a condição de plantas companheiras, ou seja, de cooperação mútua, na qual se tem um efeito benéfico entre as espécies e uma utilização máxima dos recursos ambientais (CERETTA, 1986).

O melhor desempenho agronômico da alface no policultivo ficou próximo ao obtido por Porto et al. (2011), os quais também trabalharam com o policultivo de rúcula, cenoura e alface, plantadas praticamente na mesma época e na mesma proporção de densidade populacional de 50R-50C-50A (\%) das populações recomendadas em cultivo solteiro das culturas componentes do sistema. A pequena diferença entre essas performances se deve aos fatorestratamentos testados.

\section{Cultura da cenoura}

Não houve interação significativa entre qualquer um dos fatores-tratamentos na produtividade total e comercial e nas produtividades de raízes longas, médias e curtas de cenoura (Figuras $3 \mathrm{~A}$ a $3 \mathrm{E}$ e Tabela 3). Aumentos na produtividade total e nas produtividades de raízes longas e médias de $2,63,2,15$ e $0,23 \mathrm{t} \mathrm{ha}^{-1}$ foram observados com as quantidades crescentes de flor-de-seda entre a menor $\left(10 \mathrm{t} \mathrm{ha}^{-1}\right)$ e a maior $\left(55 \mathrm{t} \mathrm{ha}^{-1}\right)$ quantidade incorporada, com valores máximos de 12,67, 5,17 e 4,78 $\mathrm{t} \mathrm{ha}^{-1}$, respectivamente (Figuras 3A, 3C e 3D). Diferentemente do comportamento dessas oleráceas, foi registrado um aumento nas produtividades de raízes comerciais, curtas e refugos com as quantidades crescentes de flor-de-seda até os valores de $11,33,1,62$ e $1,50 \mathrm{t} \mathrm{ha}^{-1}$ nas quantidades de 52,14 24,44 e $12,81 \mathrm{t} \mathrm{ha}^{-1}$, decrescendo em seguida até a última quantidade adicionada ao solo em relação às raízes comerciais e curtas e estabilizando o comportamento em relação às raízes refugos (Figuras $3 \mathrm{~B}, 3 \mathrm{E}$ e $3 \mathrm{~F})$.

A resposta crescente nas produtividades comercial e total de raízes de cenoura em função do aumento nas quantidades de flor-de-seda pode ser atribuída aos efeitos benéficos da adubação verde, no qual é possível destacar o aumento da disponibilidade de nutrientes para as culturas, a proteção do solo contra erosão, o favorecimento de organismos benéficos para agricultura e o controle de plantas espontâneas (ESPINDOLA et al., 2004). Por outro lado, o comportamento dessas produtividades evidencia que não houve forte competição interespecífica, já que a melhor performance produtiva da cenoura foi registrada nas altas populações das oleráceas, resultante do melhor aproveitamento dos recursos ambientais.

Não foi observada nenhuma diferença significativa entre os valores médios das raízes da cenoura entre as proporções de densidades populacionais das culturas componentes estudadas (Tabela 3), evidenciando que não houve qualquer influência das proporções populacionais nessas características.

Esses resultados diferiram dos obtidos por Oliveira (2012a), o qual observou que o melhor desempenho produtivo da cenoura no policultivo foi obtido na quantidade de $19,36 \mathrm{tha}^{-1}$ de jitirana incorporada no solo. A densidade populacional que proporcionou esse melhor desempenho produtivo foi a de 50R-50C-50Co (\%) das DPs dos cultivos solteiros. 
A
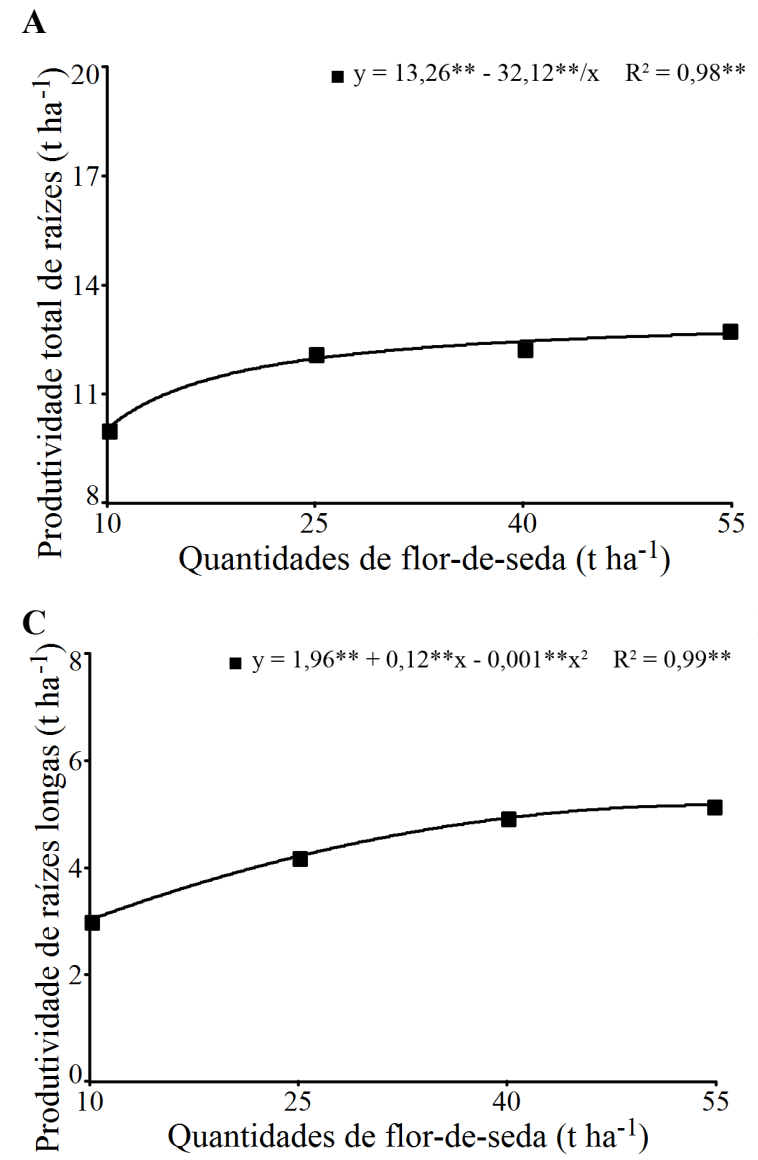

$\mathbf{E}$

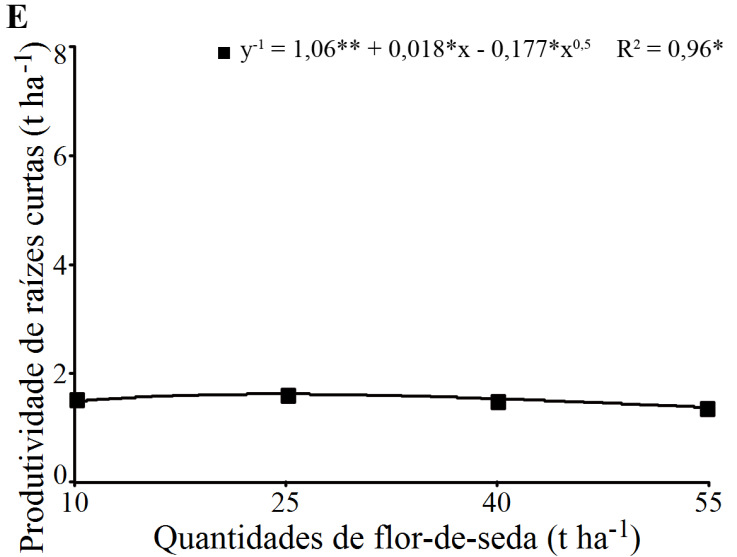

B

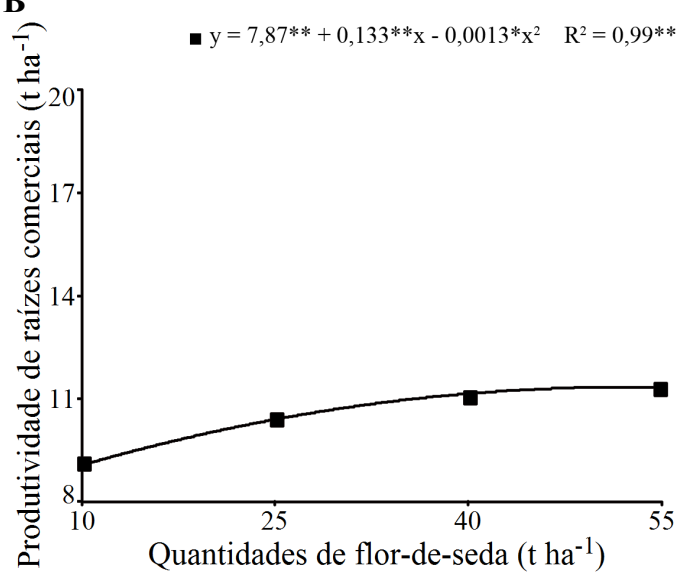

D

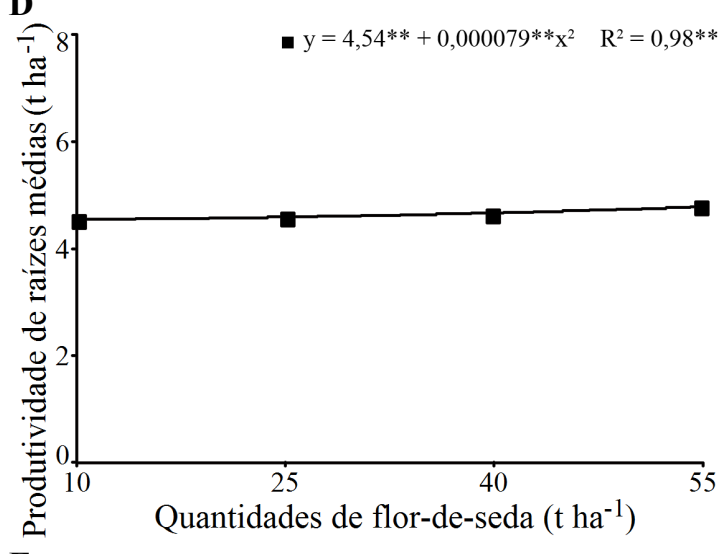

$\mathbf{F}$

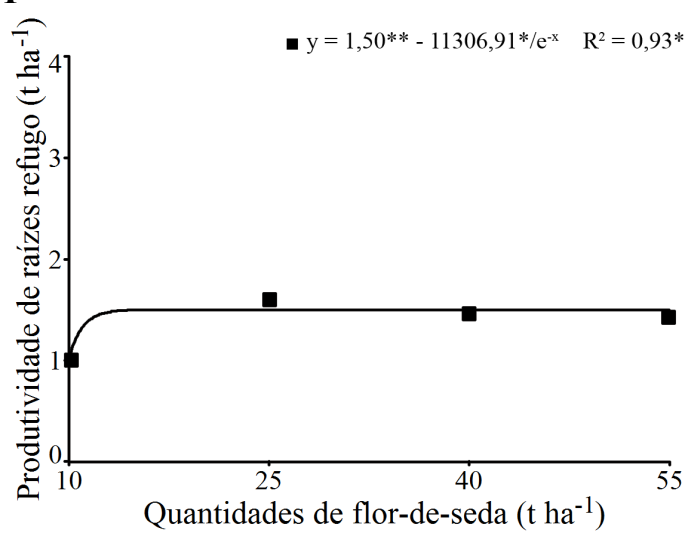

Figura 3. Produtividades total (A) e comercial (B), produtividade de raízes longas (C), médias (D) e curtas (E) e produtividade de raízes refugo (F) de cenoura consorciada com rúcula e alface. Mossoró (RN), UFERSA, 2012.

Tabela 3. Massa fresca da parte aérea (MFPA), produtividades total (PT) e comercial (PC), produtividade de raízes longas (RL), médias (RM), curtas (RC) e refugos (RR) de cenoura consorciada com rúcula e alface em diferentes proporções de densidades populacionais das culturas componentes. Mossoró (RN), UFERSA, 2012.

\begin{tabular}{|c|c|c|c|c|c|c|}
\hline $\begin{array}{c}\text { Proporções de densidades } \\
\text { populacionais }(\%)\end{array}$ & PT $\left(\mathrm{t} \mathrm{ha}^{-1}\right)$ & PC $\left(t h^{-1}\right)$ & RL $\left(\mathrm{tha}^{-1}\right)$ & $R M\left(t h^{-1}\right)$ & $\operatorname{RC}\left(\mathrm{tha}^{-1}\right)$ & $\operatorname{RR}\left(\mathrm{tha}^{-1}\right)$ \\
\hline $50-50-50$ & $11,92 \mathrm{a}$ & $10,68 \mathrm{a}$ & $4,18 \mathrm{a}$ & $4,83 \mathrm{a}$ & $1,67 \mathrm{a}$ & $1,47 \mathrm{a}$ \\
\hline $40-50-40$ & $11,82 \mathrm{a}$ & $10,40 \mathrm{a}$ & $4,39 \mathrm{a}$ & $4,62 \mathrm{a}$ & $1,38 \mathrm{a}$ & $1,42 \mathrm{a}$ \\
\hline $30-50-30$ & $11,15 \mathrm{a}$ & $10,75 \mathrm{a}$ & $4,72 \mathrm{a}$ & $4,42 \mathrm{a}$ & $1,60 \mathrm{a}$ & $1,40 \mathrm{a}$ \\
\hline $20-50-20$ & $11,23 \mathrm{a}$ & $10,13 \mathrm{a}$ & $4,02 \mathrm{a}$ & $4,72 \mathrm{a}$ & $1,38 \mathrm{a}$ & $1,12 \mathrm{a}$ \\
\hline CV (\%) & 16,11 & 16,42 & 37,61 & 23,30 & 42,65 & 21,86 \\
\hline
\end{tabular}

*Médias seguidas pela mesma letra minúscula na coluna não diferem estatisticamente entre si pelo teste de Tukey ao nível $5 \%$ de probabilidade. 


\section{Índice econômico}

Não houve interação significativa entre qualquer um dos fatores-tratamentos na vantagem monetária corrigida (Figura 4 Tabela 4). Aumento de
$\mathrm{R} \$ 3.881,62 \mathrm{ha}^{-1}$ foi observado com as quantidades crescentes de flor-de-seda entre a menor $\left(10 \mathrm{t} \mathrm{ha}^{-1}\right) \mathrm{e}$ a maior $\left(55 \mathrm{t} \mathrm{ha}^{-1}\right)$ dosagem, com valor máximo de $\mathrm{R} \$ 5.847,20 \mathrm{ha}^{-1}$ na quantidade de $55 \mathrm{t} \mathrm{ha}^{-1} \mathrm{de}$ flor-de-seda (Figura 4).

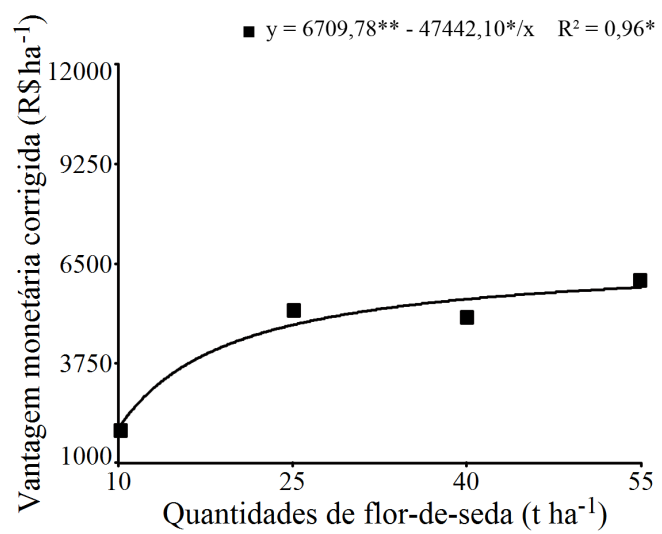

Figura 4. Vantagem monetária corrigida do policultivo de rúcula, cenoura e alface em diferentes quantidades de flor-de-seda. Mossoró (RN), UFERSA, 2012.

Os maiores valores médios para vantagem 50C-50A, sobressaindo-se das demais (Tabela 4). monetária corrigida foi obtido na proporção 50R-

Tabela 4. Vantagem monetária corrigida $\left(\mathrm{VM}_{\mathrm{c}}\right)$ em diferentes proporções de densidades populacionais da alface e rúcula consorciadas com cenoura. Mossoró (RN), UFERSA, 2012.

\begin{tabular}{lc}
\hline $\begin{array}{l}\text { Proporções de densidades } \\
\text { populacionais (\%) }\end{array}$ & $\begin{array}{l}\mathbf{V M}_{\mathbf{c}} \\
\mathbf{R S ~ h a}^{-\mathbf{1}} \mathbf{)}\end{array}$ \\
\hline $50-50-50$ & $7195,22 \mathrm{a}$ \\
$40-50-40$ & $5261,62 \mathrm{ab}$ \\
$30-50-30$ & $3823,89 \mathrm{bc}$ \\
$20-50-20$ & $1867,87 \mathrm{c}$ \\
\hline $\mathrm{CV}(\%)$ & 58,41 \\
\hline \multirow{2}{*}{ *Médias seguidas de letras minúsculas diferentes na coluna diferem estatisticamente entre si } \\
pelo teste de Tukey ao nível de 5\% de probabilidade.
\end{tabular}

Esse resultado do índice econômico evidencia a superioridade agronômica-biológica em relação às culturas solteiras pelo uso favorável dos recursos ambientais em todas as proporções populacionais. Esse favorecimento pode ser explicado pelas observações de Caballero et al. (1995) ao considerarem que quando a UET for maior que 1 o consórcio favorecerá o crescimento e a produção das culturas componentes. As vantagens monetárias corrigidas obtidas na maior quantidade de flor-de-seda adicionada ao solo e na mais alta proporção de densidade populacional foram superiores às obtidas por Bezerra Neto et al. (2010) trabalhando com a associação de cenoura e alface na mesma época de cultivo. Essa diferença foi proporcionada pela eficiência do policultivo na utilização do adubo verde, bem como da maior eficiência da mais alta densidade populacional na utilização dos recursos ambientais.

\section{CONCLUSÕES}

O uso da flor-de-seda como adubo verde se mostrou viável no policultivo de rúcula, cenoura e alface.

A melhor eficiência do policultivo de rúcula, cenoura e alface foi registrada na quantidade de $55 \mathrm{t}$ $\mathrm{ha}^{-1}$ de flor-de-seda incorporada ao solo.

A proporção de densidade populacional de rúcula, cenoura e alface de 50R-50C-50A (\%) das populações recomendadas em seus cultivos solteiros foram as que proporcionaram a maior eficiência agronômica do policultivo entre elas.

\section{REFERÊNCIAS}

BEZERRA NETO, F. et al. Associação de densidades populacionais de cenoura e alface no desempenho agronômico da cenoura em cultivo consorciado em faixa. Horticultura Brasileira, Brasília, v. 23, n. 2, p. 233-237, 2005.

BEZERRA NETO, F. et al. Desempenho agronômico da alface em diferentes quantidades e tempos de decomposição de jitirana verde. Agrária, Recife, v. 
6, n. 2, p. 236-242, 2011.

BEZERRA NETO, F. et al. Evaluation of yield advantage indexes in carrot-lettuce intercropping systems. Interciencia, Caracas, v. 35, n. 1, p. 59-64, 2010 .

BEZERRA NETO, F.; GOMES, E. G.; OLIVEIRA, A. M. Produtividade biológica em sistemas consorciados de cenoura e alface avaliada através de indicadores agroeconômicos e métodos multicritério. Horticultura Brasileira, Brasília, v. 25, n. 2, p. 193-198, 2007.

BEZERRA NETO, F. et al. Otimização agroeconômica da cenoura fertilizada com diferentes doses de jitirana. Revista Ciência Agronômica, Fortaleza, v. 45, n. 2, p. 305-311, 2014.

CABALLERO, R.; GOICOECHEA, E. L.; HERMAIZ, P. J. Forage yields and quality of common vetch and oat sown at varying seeding ratios and seeding rates of common vetch. Field Crops Research, Amsterdam, v. 41, n. 2, p. 135-140, 1995.

CARMO FILHO, F.; ESPÍNOLA SOBRINHO, J.; MAIA NETO, J. M. Dados climatológicos de Mossoró: um município semi-árido nordestino. Mossoró: UFERSA, 1991. 121 p. (Coleção Mossoroense, C. $30)$.

CERETTA, C. A. Sistemas de cultivo de mandioca em fileiras simples e duplas em monocultivo e consorciada com girassol. 1986. 126 f. Dissertação (Mestrado em Agronomia: Área de Concentração em Horticultura) - Universidade Federal do Rio Grande do Sul, Porto Alegre, 1986.

CHOAIRY, S. A.; FERNANDES, P. D. Densidade de plantio na cultura do abacaxi. Pesquisa Agropecuária Brasileira, Brasília, v. 18, n. 9, p. 985-988, 1983.

EMBRAPA. Centro Nacional de Pesquisa de Solos. Sistema brasileiro de classificação de solos. 2.ed. Rio de Janeiro: EMBRAPA-SPI, 2006. 306 p.

ESPÍNDOLA, A. A. A.; ALMEIDA, D. L.; GUERRA, J. G. M. Estratégias para utilização de leguminosas para adubação verde em unidades de produção agroecológica. Seropédica: Embrapa Agrobiologia, 2004. 24 p. (Embrapa Agrobiologia. Documentos, 174).

FEDERER, W. T. Statistical issues in intercropping. In: EL-SHAARAWI, A.H.; PIEGORSCH, W.W., PIEGORSCH, W. (Eds). Encyclopedia of environmetrics. $1^{\text {st }}$ edition, New York: Wiley, 2002. p.1064-1069.
FERREIRA, D. F. Sisvar: A computer statistical analysis system. Ciência e Agrotecnologia, Lavras, v. 35, n. 6, p. 1039-1042, 2011.

FILGUEIRA, F. A. R. Novo manual de olericultura: Agrotecnologia moderna na produção e comercialização de hortaliças. 2. ed. Viçosa, MG: UFV, 2003. $412 \mathrm{p}$

FREITAS, K. K. C. et al. Desempenho agronômico de rúcula sob diferentes espaçamentos e épocas de plantio. Revista Ciência Agronômica, Fortaleza, v. 40, n. 3, p. 449-454, 2009.

GÓES, S. B. Desempenho agroeconômico de alface lisa em função de quantidades de jitirana incorporadas ao solo e de seus tempos de decomposição. 2007. 80 f. Dissertação (Mestrado em Agronomia: Fitotecnia: Área de Concentração em Agricultura Tropical) - Universidade Federal Rural do Semi-Árido, Mossoró, 2007.

GÓES, S. B. et al. Productive performance of lettuce at different amounts and times of decomposition of dry scarlet starglory. Revista Ciência Agronômica, Fortaleza, v. 42, n. 4, p: 1036-1042, 2011.

JANDEL SCIENTIFIC. Table Curve: curve fitting software. Corte Madera, CA: Jandel Scientific, 1991. $280 \mathrm{p}$.

LANA, M. M.; VIEIRA, J. V. Fisiologia e manuseio pós-colheita de cenoura. Brasília: Embrapa Hortaliças, 2000. 16 p. (Circular Técnica 21).

LIMA. E. F. Produtividade e rentabilidade da alface adubada com flor-de-seda. 2012. 65 p. Dissertação (Mestrado em Produção Vegetal: Área de Concentração em Produção Vegetal no Semiárido) - Universidade Federal Rural de Pernambuco. Serra Talhada. PE. 2012.

LIMA, J. S. S. et al. Produtividade da cenoura, coentro e rúcula em função de densidades populacionais. Revista Verde de Agroecologia e Desenvolvimento Sustentável, Mossoró, v. 8, n.1, p. 110-116, 2013.

LIMA, V. I. A. et al. Viabilidade agroeconômica do cultivo consorciado de coentro, alface e rúcula sob diferentes arranjos espaciais. Enciclopédia Biosfera, Goiânia, v. 10, n. 18, p. 3060-3065, 2014.

LINHARES, P. C. F. Produção de rúcula em função de diferentes quantidades e tempos de decomposição de jitirana. 2007. 58 f. Dissertação (Mestrado em Fitotecnia: Área de Concentração em Agricultura Tropical) - Universidade Federal Rural do Semi-Árido, Mossoró, 2007.

LINHARES, P. C. F. et al. Quantidades e tempos de 
decomposição da jitirana no desempenho agronômico do coentro. Ciência Rural, Santa Maria, v. 42, n. 2, p. 243-248, 2012.

LINHARES, P. C. F. et al. Otimização da quantidade de jitirana incorporada ao solo no rendimento do rabanete. Agropecuária Científica no Semi-Árido, Patos, v. 9, n. 2, p. 42-48, 2013.

LINHARES, P. C. F. et al. Velocidade de decomposição da flor-de-seda no desempenho agronômico da rúcula cv. cultivada. Revista Verde de Agroecologia e Desenvolvimento Sustentável, Mossoró, v. 4, n. 2, p. 46-50, 2009.

LOPES, W. A. R. et al. Produtividade de cultivares de cenoura sob diferentes densidades de plantio. Revista Ceres, Viçosa, v. 55, n. 5, p. 482-487, 2008.

NOVAES, R. F. et al. Fertilidade do solo. In: MEURER, E. J. Fatores que influenciam o crescimento e o desenvolvimento das plantas. Viçosa: SBCS, p. 65-90, 2007.

OLIVEIRA, L. J. Viabilidade agroeconômica do bicultivo de rúcula e coentro consorciado com cenoura em função de quantidades de jitirana e densidades populacionais. 2012a. 102f. Tese (Doutorado em Fitotecnia: Área de Concentração em Agricultura Tropical) - Universidade Federal Rural do Semi-Árido, Mossoró, 2012a.

OLIVEIRA, M. K. T. et al. Desempenho agroeconômico da cenoura adubada com jitirana (Merremia aegyptia). Horticultura Brasileira, Brasília, v. 30, n. 3, p. 433-439, 2012 b.

PEREIRA, M. F. S. et al. Diferentes doses de jitirana em cobertura como adubo verde na produtividade de rúcula. Revista Verde de Agroecologia e Desenvolvimento Sustentável, Mossoró, v. 6, n. 2, p. 93-97, 2011.

PORTO, V. C. N. et al. Combination of lettuce and rocket cultivars in two cultures intercropped with carrots. Horticultura Brasileira, Brasília, v. 29, n. 3, p. 404-411, 2011.

REZENDE, B. L. A. et al. Análise econômica de cultivos consorciados de alface e americana $\mathrm{x}$ rabanete: um estudo de caso. Horticultura Brasileira, Brasília, v. 23, n. 3, p. 853-858, 2005.

SILVA, M. L. et al. Produção de cenoura fertilizada com flor-de-seda (Calotropis procera (Ait.) R.Br.). Revista Ciência Agronômica, Fortaleza, v. 44, n. 4, p. 732-740, 2013.

SILVA, M. G. et al. Efeito da solarização, adubação química e orgânica no controle de nematóides em alface sob cultivo protegido. Horticultura Brasileira, Brasília, v. 24, n. 4, p. 489-494, 2006.

SILVA, A. F. A. et al. Rentabilidade do rabanete adubado com flor-de-seda em duas épocas de cultivo no semiárido de Pernambuco. Revista de Ciências Agrárias/Amazonian Journal of Agricultural and Environmental Sciences, v. 58, n. 2, p. 198-207, 2015.

TAVELLA, L. B. et al. Cultivo orgânico de coentro em plantio direto utilizando cobertura viva e morta adubado com composto. Revista Ciência Agronômica, Fortaleza, v. 41, n. 4, p. 614-618, 2010 . 